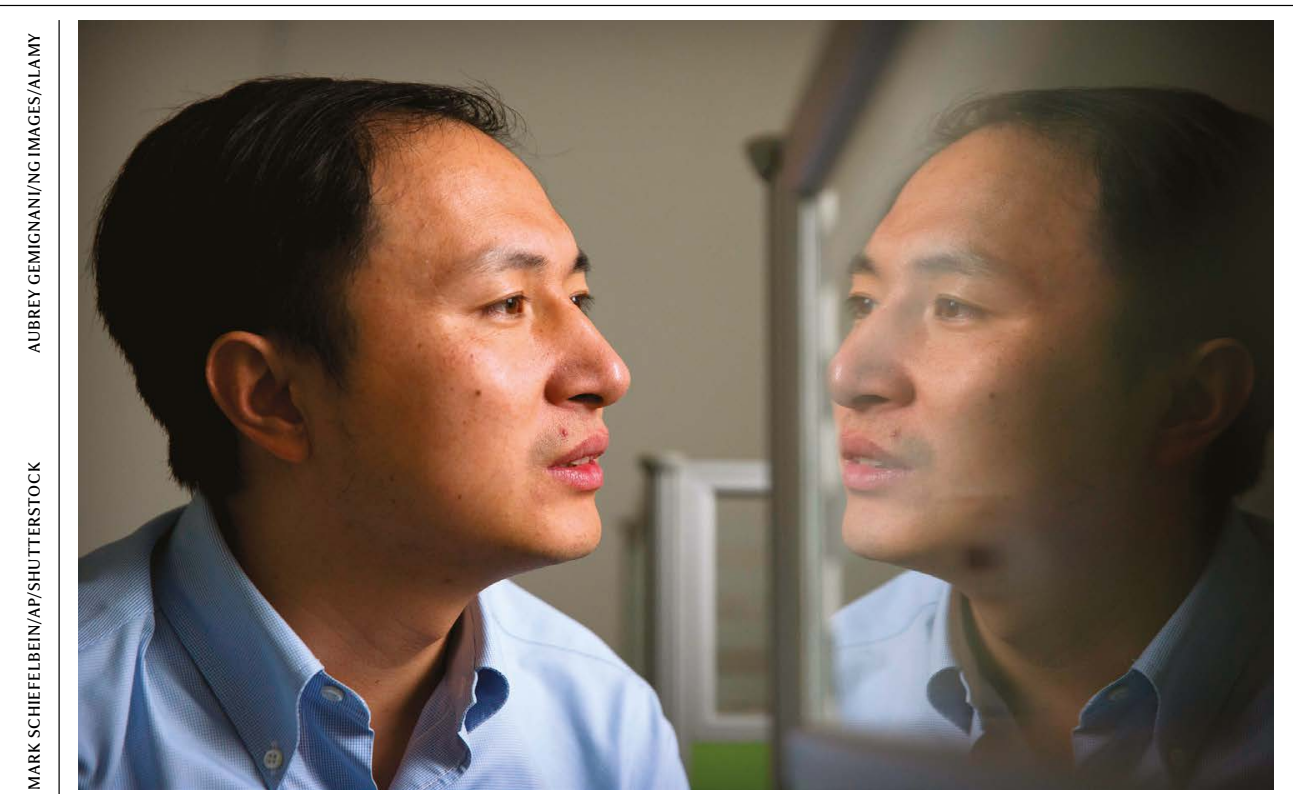

He Jiankui stunned the world when he declared that he'd created the first gene-edited babies.

The court fined He 3 million yuan (US\$430,000). Collaborators Zhang Renliand QinJinzhou received less severe punishments.

The health ministry has also banned the researchers from working with human reproductive technology again, and the science ministry has banned them from applying for research funding, according to Xinhua.

Scientists in China who are currently researching into CRISPR's potential to treat various genetic diseases by modifying cells other than those of embryos say that they fear He's actions might have a detrimental effect on their work, too, even though it is not as ethically contentious. He shocked the world's scientists in November 2018 when he announced that his team at Southern University of Science and Technology in Shenzhen had used CRISPR to edit DNA in human embryos to make them less susceptible to HIV. The edits were designed to disrupt a gene that encodes a protein allowing HIV to enter immune cells.

Scientists condemned He's actions, saying that gene-editing technology was too premature to be used for reproductive purposes. They also said the experiment was problematic because it risked introducing a mutation with potentially harmful effects while offering little benefit - the babies were not at high risk of contracting HIV. In the wake of the scandal, researchers called for a moratorium on gene editing in embryos and germline cells.

At the time, Chinese law academics told Nature that He could face a range of criminal charges, including practising medicine without adequate qualifications, forging ethics documents and skirting laws banning the use of assisted reproductive technologies in people with HIV. He was fired by his university in January last year.

The court's announcement puts to rest the suspicions of some researchers that the government would not bring a criminal case against He because of the increased media attention it would generate, says Tang $\mathrm{Li}$, a science-policy researcher at Fudan University in Shanghai. Discussion of He's experiments was widely censored on Chinese social media. But Tang says the disclosure of the court's result demonstrates China's commitment on research ethics. This is a big step forward in promoting responsible research, she says.

Although an unpublished manuscript describing the experiments lists ten authors, according to MIT Technology Review, He, Zhang and Qin are the only ones to face penalties so far. The manuscript says Zhang "performed the human embryo microinjections", MIT Technology Review reports. Zhang, who was affiliated with the Guangdong Academy of Medical Sciences and Guangdong General Hospital in Guangzhou at the time of the experiments, has been sentenced to two years in prison and fined one million yuan. Qin, an embryologist at Southern University of Science and Technology who was named as the applicant on the experiment listed on China's clinical-trial website, was given an 18-month suspended prison sentence and fined 500,000 yuan, according to Xinhua. Wei says it is unlikely that He will work again as a researcher at a Chinese institution.

The trio's punishments send a powerful message to other researchers doing any type of gene-editing work in clinical trials in China, says Lu You, an oncologist at Sichuan University in Chengdu. His team was the first to test CRISPR gene-editing in humans, in a clinical trial that modified adult - not embryonic cells taken from people with lung cancer (see page 156). "If I was a newcomer, a researcher wishing to start gene-editing research and clinical trials, the case would be enough to alert me to the cost of such violations," he says.

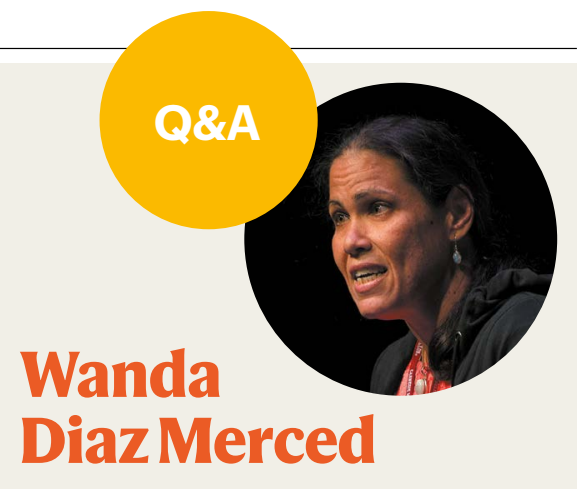

Astronomy is inextricably associated with colourful images of the cosmos. But Wanda Diaz Merced says that neglecting senses other than sight can mean missing out on discoveries. Diaz Merced, an astronomer at the International Astronomical Union (IAU) Office for Astronomy Outreach in Mitaka, Japan, is a pioneer of sonification, a technique that converts aspects of data, such as frequency, into audible elements. It could help astronomers to avoid biases from interpreting data only visually, argues Diaz Merced, who lost her sight in her twenties. At an IAU meeting on equality and diversity in Mitaka last December, Diaz Merced spoke to Nature about the approach.

How did you begin working on sonification? As an intern at NASA in 2005, I created a tool to map astronomical data into sound - pitch, rhythm and volume. In my 2013 $\mathrm{PhD}$ dissertation, I proved that it is useful.

\section{How did you do that?}

I presented users with spectral data and asked them to look for a double peak that indicates a black hole. People tried to identify signals using vision only, audio only and by combining vision and sound. We found that combining audio with visual interaction was the most sensitive way.

\section{How can sonification be used?}

It can help us to study the habitability of an exoplanet, by understanding how high-energy rays interact with its magnetic field or atmosphere. Such interactions cause fluctuations of electromagnetic emission from the star that vary with frequency.

Are astronomers using this approach? People are making a bit more of an effort. My collaborators and I are analysing and developing sonification software designed around the user's experience. Now we have to provide the field with the evidence to help researchers to change their mindset.

\section{Interview by Elizabeth Gibney}

This interview has been edited for length and clarity. 